\title{
Evaluation of Pneumatic Bulge Test Experiments and Corresponding Numerical Forming Simulations
}

\author{
Jens Kappes and Mathias Liewald \\ Institute for Metal Forming Technology (IFU), Holzgartenstr. 17, Stuttgart 70174, Germany
}

Received: April 13, 2011 / Accepted: April 26, 2011 / Published: September 25, 2011.

\begin{abstract}
Superplastic forming of sheet metal exhibits numerous technical and economical advantages for manufacturing complex part geometries, which enables the potential of lightweight production (e.g., of vehicle bodies), especially for niche types. Within virtual engineering tasks, material parameters in combination with numerical sheet metal forming simulations are crucial. In such context, the selected testing procedure should be as similar as possible to the subsequent forming technique. For that reason the pneumatic bulge test represents an appropriate testing procedure for the most common superplastic sheet metal forming process, the blow-forming process [1-4]. This paper deals with pneumatic bulge test experiments at constant forming pressures using the aluminum alloy AA5083 (initial sheet thickness $\mathrm{s}_{0}=1.5 \mathrm{~mm}$ ). Due to in-situ measurement of strains in pneumatic bulging, material parameters can be determined. These material parameters can be used for an interpolation, in this case the power law, to determine material constant $C$, strain-hardening exponent $n$ and strain-rate sensitivity index $m$ using the least square error method. Furthermore, the superplastic forming process was simulated by FE modeling with material parameters exclusively determined from pneumatic bulging. The comparison of numerical and experimental results showed good correlation for the observed conditions.
\end{abstract}

Key words: Superplastic, pneumatic bulge test, in-situ strain measurement, numerical forming simulation.

\section{Introduction}

Superplastic sheet metal forming is characterized by achievable high strains which enable the production of otherwise difficult-to-manufacture or non-manufacturable complex part geometries. The blow-forming process (Fig. 1) represents a common principle of superplastic sheet metal forming: A circumferentially clamped and heated sheet is blow-formed by means of gas pressure [5, 6].

Low tool costs, high design complexity coupled with low forming speeds make this forming process attractive, especially for small lot sizes [7].

Up to now in "academic environment" a variety of uni-axial tensile tests at elevated temperatures [8-16] and pneumatic bulge test experiments $[1,2,4,15$, 17-24] have been done to determine material parameters concerning superplastic forming processes. But

Corresponding author: Jens Kappes, research field: superplastic sheet metal forming. E-mail: Jens.Kappes@ifu.uni-stuttgart.de. due to small lot sizes, the effort and budget in "industrial environment” for designing superplastic forming processes are limited. For this reason the tool design and corresponding pressure profiles in superplastic forming processes are usually based on trial and error [21, 25]. Consequently a procedure should be established to determine superplastic material and process parameters accurately and efficiently to permit designing superplastic forming processes to be reliable and attractive. The pneumatic bulge test, combined with in-situ strain measurement and numerical simulation, can meet these requirements very close to praxis. Ergo, pneumatic bulge test experiments with different forming pressures were carried out to determine the relevant material parameters for numerical superplastic forming simulation.

\section{Pneumatic Bulge Test Results}

The experimental device for the pneumatic bulge tests has a die opening diameter of $100 \mathrm{~mm}$ and an edge 


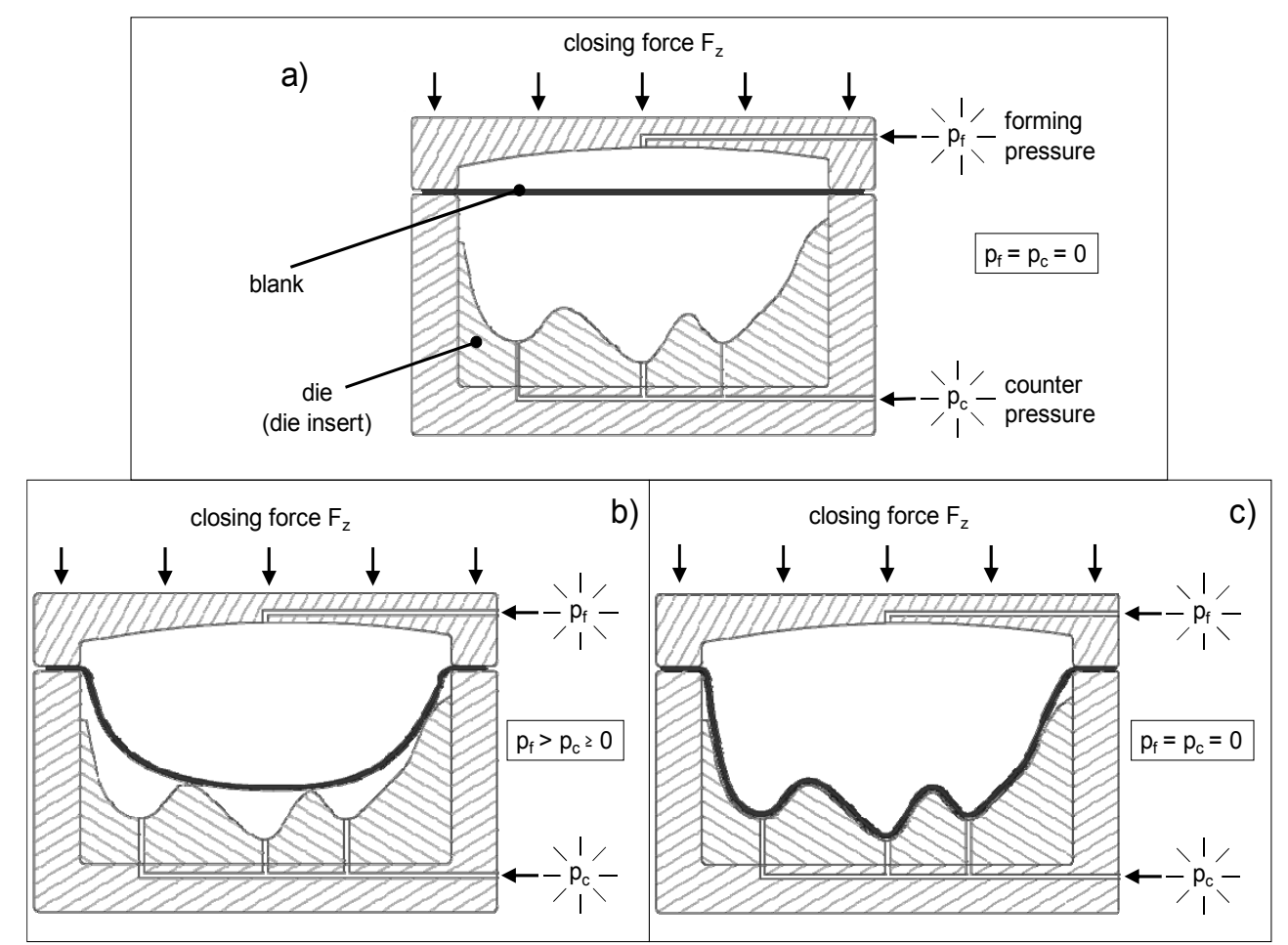

Fig. 1 Superplastic sheet metal forming: schematic of the blow-forming process.

radius of $5 \mathrm{~mm}$. The blank holder has to prevent material flow into the forming zone and to ensure expansion of the sheet only into the die opening. The tool is heated and the specimen is interposed unheated; there is therefore a period of time of about one minute between clamping and pressurizing. Aluminum alloy AA5083 $\left(\mathrm{s}_{0}=1.5 \mathrm{~mm}\right)$ and a constant forming temperature of about $500{ }^{\circ} \mathrm{C}$ were chosen for the pneumatic bulge test experiments. For in-situ measurement of strains, GOM's photogrammetric system ARAMIS 5M was used. For this reason a grid was applied on the surface of the specimen facing the die. The grid consists of black paint and a stochastic laser grid and represents the forming conditions of a sheet lubricated with boron nitride (cp. [26]).

During superplastic sheet metal forming, strain rate is not constant over the entire forming zone-in case of pneumatic bulging (circular die), effective strain rates increase from the dome edge to the dome apex (neglecting the beginning of the forming process). For this reason, different forming pressures were chosen to determine the material parameter determination regar- ding pneumatic bulging in order to consider the strain rate range over the forming zone.

Pneumatic bulge test experiments were done using different constant forming pressures $(0.2 ; 0.25 ; 0.3$; $0.33 \mathrm{MPa}$ ) to achieve different strain rates in the dome apex. A multitude of measurements resulted from these experiments from every single bulge test experiment, due to the in-situ strain measurement. These measurements refer to the dome apex of the specimen (the dome is selected as stage point and analyzed over the whole forming process) and consist of the biaxial flow stress according to the strain and the strain rate at the same moment. This results mathematically in many measured points in a three-dimensional coordinate system with effective strain on the $\mathrm{X}$-axis, effective strain rate on the $\mathrm{Y}$-axis and biaxial flow stress on the Z-axis.

Generally, the superplastic flow at constant temperatures is described by an enhancement of the approximation according to Ludwik (the power law) [5, 18, 27, 28]:

$$
k_{f}=C \cdot \varepsilon^{n} \cdot \dot{\varepsilon}^{m}
$$


where $k_{f}$ is the flow stress, $C$ is the material constant, $\varepsilon$ is the true effective strain (v. Mises), $\dot{\varepsilon}$ is the true effective strain rate (v. Mises), $n$ is the strain-hardening exponent and $m$ is the strain-rate sensitivity index.

To determine material constant $C$, strain-hardening exponent $n$ and strain-rate sensitivity index $m$, an interpolation of the measured points, in this case via the power law, can be done using the least square error method. Linear equations are easier to handle, and for this reason the power law (1) is linearized to

$$
\ln \left(k_{f}\right)=[\ln (C)]+[n \cdot \ln (\varepsilon)]+[m \cdot \ln (\dot{\varepsilon})]
$$

Substitution of Eq. (2) results into

$$
z=D+n \cdot x+m \cdot y
$$

respectively

$$
z_{i}=D+n \cdot x_{i}+m \cdot y_{i}
$$

where the index $i$ corresponds to the quantity of measured points $(I=1,2, \ldots$, a). With that in view, the goal function (error function $S$ ) can be described by

$$
\begin{aligned}
S(D, n, m) & =\sum_{i=1}^{a}\left[z_{i}-\left(D+n \cdot x_{i}+m \cdot y_{i}\right)\right]^{2} \\
& =\sum_{i=1}^{a} s_{i}^{2} \rightarrow \min
\end{aligned}
$$

Eq. (4) can also be written as

$$
\begin{aligned}
\vec{z}=\left(\begin{array}{c}
z_{1} \\
z_{2} \\
\ldots \\
z_{i} \\
\ldots \\
z_{a}
\end{array}\right) & =\underbrace{\left(\begin{array}{ccc}
1 & x_{1} & y_{1} \\
1 & x_{2} & y_{2} \\
\ldots & \ldots & \ldots \\
1 & x_{i} & y_{i} \\
\ldots & \ldots & \ldots \\
1 & x_{a} & y_{a}
\end{array}\right)}_{A} \cdot \underbrace{\left(\begin{array}{c}
D \\
n \\
m
\end{array}\right)}_{\vec{l}}+\left(\begin{array}{c}
s_{1} \\
s_{2} \\
\cdots \\
s_{i} \\
\ldots \\
s_{a}
\end{array}\right) \\
& \Leftrightarrow \vec{z}=A \cdot \vec{l}+\vec{s}
\end{aligned}
$$

The vector $\vec{l}$ (respectively $D, n$ and $m$ ) can be determined by the following Eq. (6) due to Eq. (4) and Eq. (5) [29]:

$$
\vec{l}=\left(A^{T} \cdot A\right)^{-1} \cdot A^{T} \cdot \vec{z}
$$

The MATLAB or Microsoft Excel programs can help in calculating Eq. (6) because of the amount of the measured points.

Before starting the calculation it is important to define which measured points should be used and how these measured points are evaluated. In this case, the surface of the undeformed sheet at room temperature, which faces the die, represents the reference plane. The strain reference ( $\varepsilon=0$ ) is defined by the lightly bulged specimen due to the thermal expansion of the sheet during heating and before pressurizing. To ensure preferable good quality of the measured points, an interval for the dome height from 15 to $50 \mathrm{~mm}$ was defined for valid measured points, at the beginning of pneumatic bulge tests the calculation of the curvature of the specimen (respectively the flow stress) is not accurate. At the end of the forming process strain rate will clearly increase due to extensive thinning.

The following results are based on a total of eight bulge test experiments using the mentioned forming pressures. Around 200 uniformly distributed measured points from every one of these experiments within the defined interval were chosen for the following evaluation. These original measured points are used, and smoothing only takes place by interpolation via the power law. Table 1 shows a Microsoft Excel graph of determined values of the material constant $C$, the strain-hardening exponent $n$ and the strain-rate sensitivity index $m$. These results were cross-checked via MATLAB.

Remarkable for superplastic forming processes is the relatively high value of the strain-hardening exponent $n$. Due to the power law [Eq. (1)], which was used for the interpolation, the influence of strain on the flow stress was also taken into account. If there had been no strain influence, the strain-hardening exponent would have dropped to zero.

In order to quantify the quality level of the interpolation, the relative frequencies (of occurrence) versus the relative deviations of the interpolation is shown in Fig. 2. 
Table 1 Determined material parameters, AA5083, $\mathrm{s}_{0}=1.5$ mm.

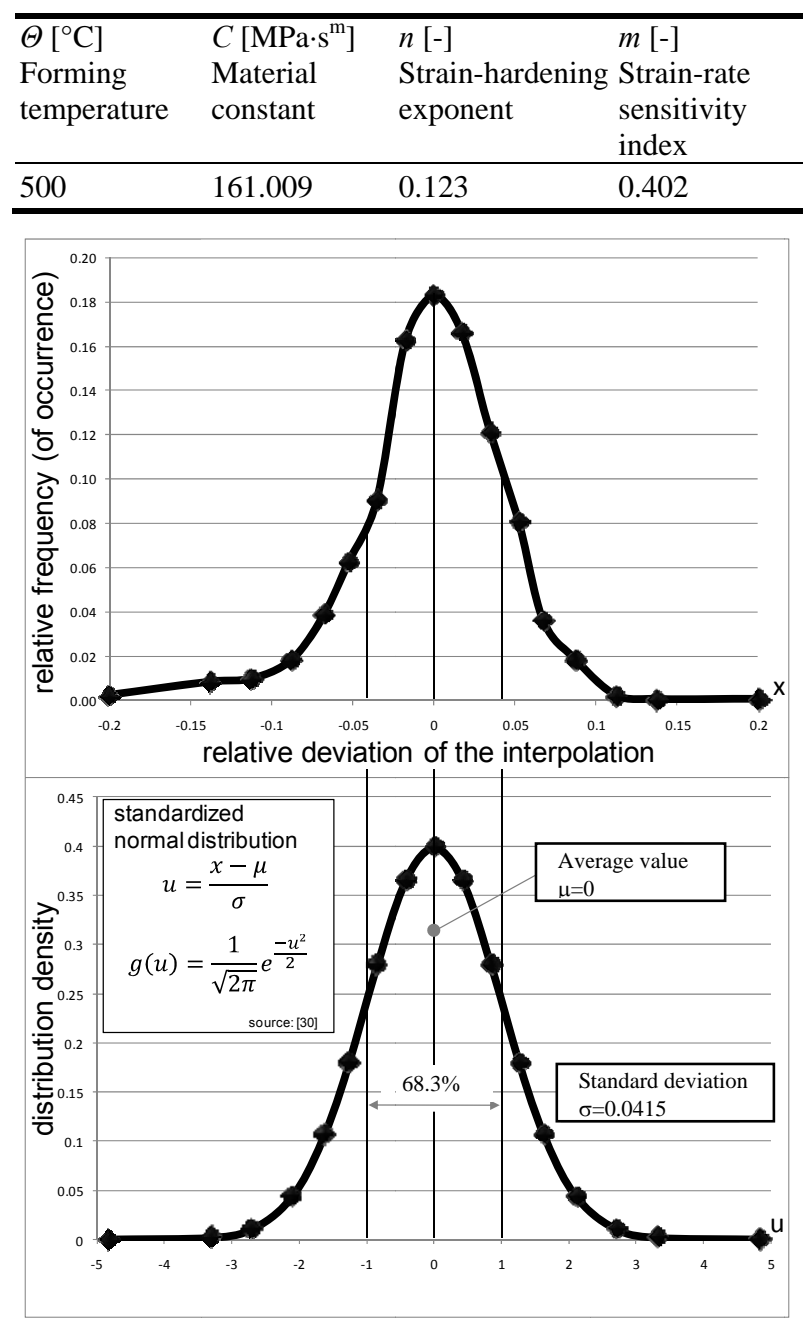

Fig. 2 Quantitative evaluation of the interpolation.

Obviously, the deviations of the interpolation from the measured points meet a normal distribution in good approximation.

\section{Numerical Simulation of Pneumatic Bulging}

Due to the determined material parameters, pneumatic bulging using a constant forming pressure of $0.33 \mathrm{MPa}$ and a forming temperature of $500{ }^{\circ} \mathrm{C}$ has been simulated. For numerical simulation, the FEA code PAM-STAMP 2G Professional 2009.0.1 was used. For this kind of forming simulation, the superplastic material law should be applied. It uses:

- elastic-plastic decomposition;
- isotropic elasticity law;

- orthotropic equivalent yield stress function (Hill 1948);

- flow rule (associative) [31].

Fig. 3 shows the material properties. Attention should be paid to the unit system. In this case the unit system mm.kg.ms was used. For this reason, e.g., the material constant $C$ from Table 1 has to be transformed to the value $K$ in Fig. 3.

Strain-rate control was deactivated in the simulation because the experiment with constant forming pressure was to be simulated.

Three criteria were chosen to evaluate the simulation results:

- effective strain at the dome apex;

- dome height;

- forming time.

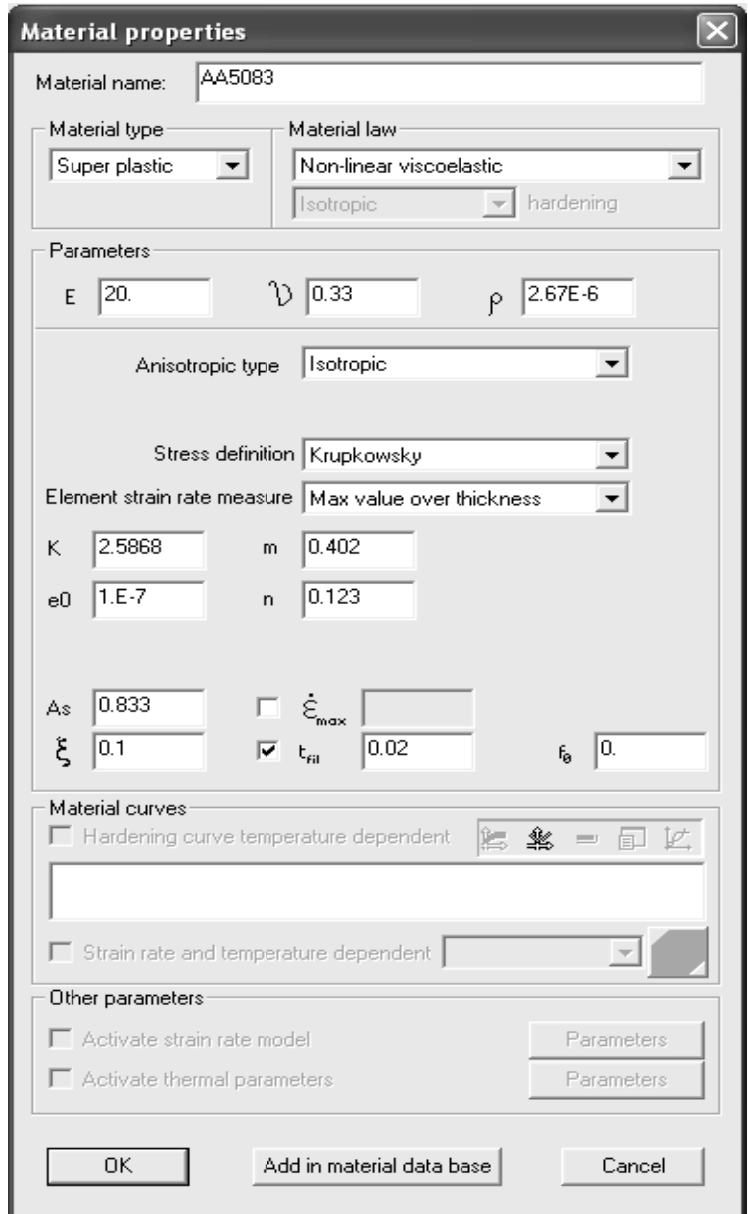

Fig. 3 Material properties used for simulation. 


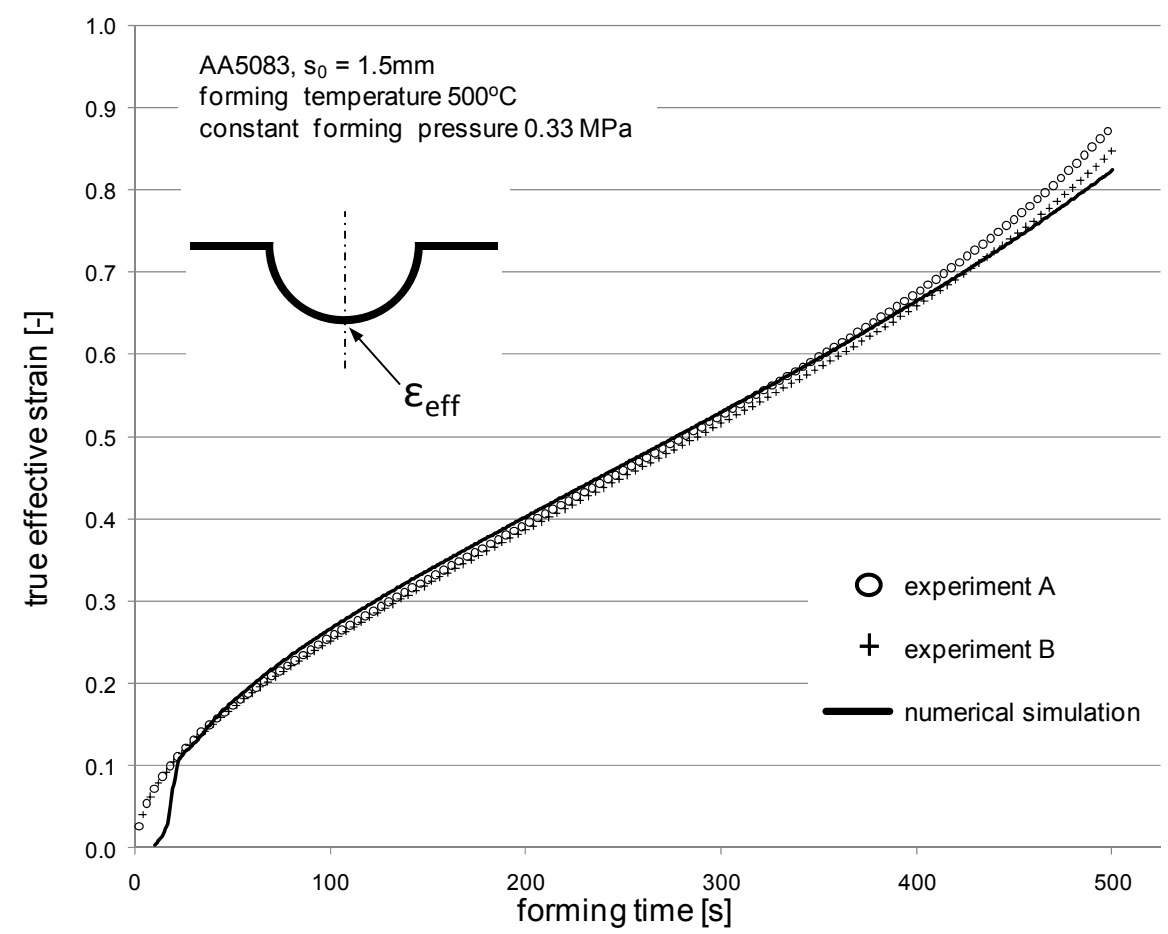

Fig. 4 Development of effective strain in the dome apex during forming.

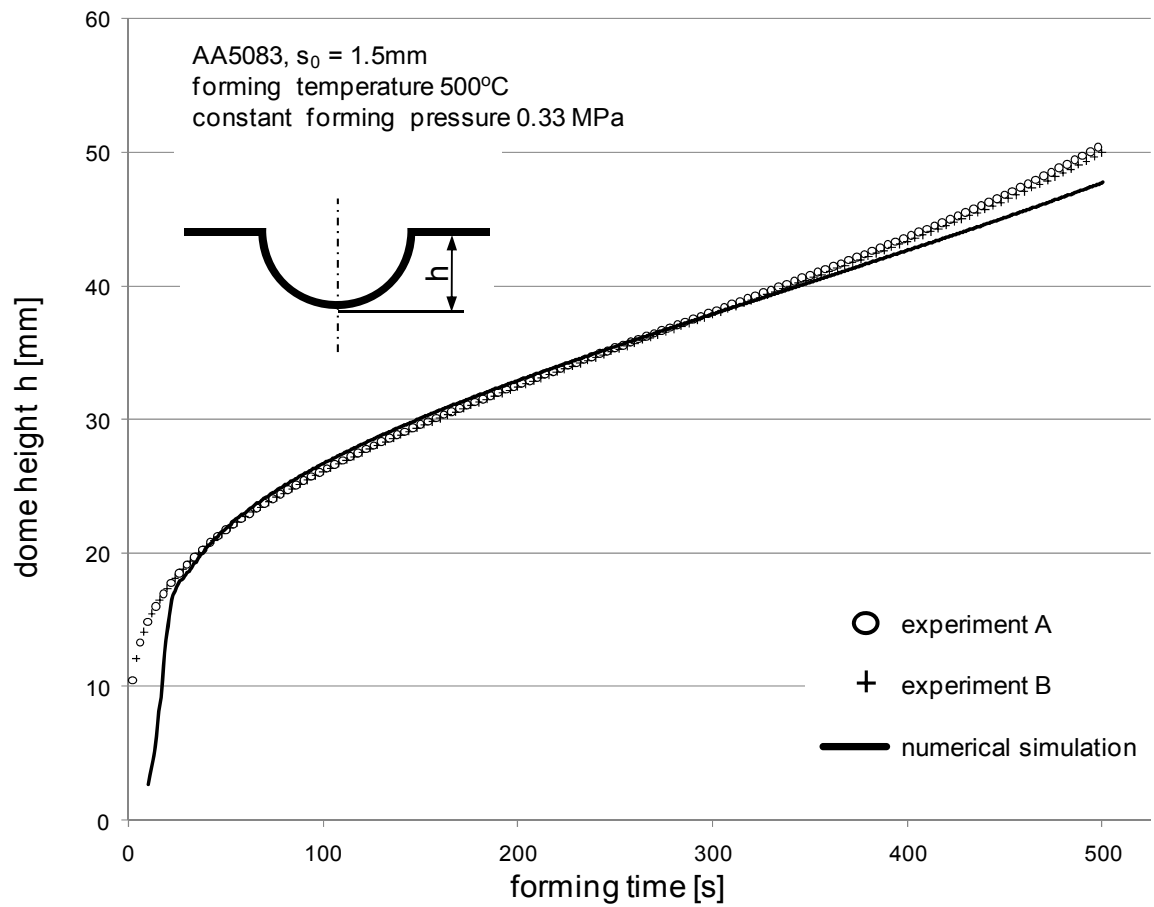

Fig. 5 Development of the dome height during forming.

These criteria adequately depict pneumatic bulging, on the one hand the effective strain combined with the forming time represents the strain development in the dome apex. On the other hand, dome height combined with forming time represents strain distribution over the forming zone. The forming pressure does not have to be considered due to its constancy. Whereas thermal expansion of the sheet during heating and before 
pressurizing was considered by material characterization, it was neglected in simulation, because the effect is negligible and consideration has to be done manually, thereby making the results less reproducible.

Fig. 4 shows the effective strain in the dome apex versus the forming time. The circles and crosses represent measurements from two pneumatic bulge test experiments up to the dome height of $50 \mathrm{~mm}$. The black line represents results from the numerical simulation. Obviously, numerical results show good correlation with the experiments.

Fig. 5 shows corresponding dome height versus the forming time. Numerical results also show good correlation with the experiments.

Especially important when forming bulge test specimens more than $50 \mathrm{~mm}$ dome height, the increasing difference between experiment and simulation after $450 \mathrm{~s}$ should be taken into account. This difference indicates that the determined material parameters are not optimal for higher strains/pole heights and the constant forming pressure of 0.33 MPa. Ways of solving this problem could be the choice of another interval for the interpolation (not only from 15 to $50 \mathrm{~mm}$ pole height) or different (/lower) forming pressures, or an adapted weighting of measured points.

\section{Conclusions and Outlook}

The approach introduced of determining material parameters from pneumatic bulging presents an attractive method to determine material parameters with regard to superplastic sheet metal forming. Material parameters were determined and used for numerical simulation (PAM-STAMP 2G) using the example of AA5083. The comparison of simulation and experimental results showed good correlation for the observed conditions.

Further research will focus on an optimum experimental procedure for determining material parameters via pneumatic bulging even more efficiently, i.e., to answer the question, if a sheet is to be formed superplastically (e.g., with a strain rate about $0.001 \mathrm{~s}^{-1}$ ) then what is the minimum required bulge test amount and what should the forming pressure paths look like?

\section{Acknowledgments}

This work on pneumatic bulging at the Institute for Metal Forming Technology (IFU) was kindly supported by the following companies: AMAG rolling GmbH, GOM (Gesellschaft für Optische Messtechnik $\mathrm{mbH}$ ) and ESI (Engineering System International) $\mathrm{GmbH}$.

\section{References}

[1] F.K. Abu-Farha, N.A. Shuaib, M.K. Khraisheh, K.J. Weinmann, Limiting strains of sheet metals obtained by pneumatic stretching at elevated temperatures, CIRP Annals-Manufacturing Technology 57 (2008) 275-278.

[2] M. Alderman, A.J. Barnes, R. Bhayani, R. Cottam, Superplastic forming of magnesium sheet alloys, in: Proceeding of IMA Taiyuan Global Magnesium Conference and Exhibition, 2009, pp. 206-215.

[3] G. Giuliano, S. Franchitti, The determination of material parameters from superplastic free-bulging tests at constant pressure, International Journal Machine Tools and Manufacture 48 (2008) 1519-1522.

[4] J.T. Carter, P.E. Krajewski, R. Verma, The hot blow forming of AZ31 Mg sheet: formability assessment and application development, Journal of the Minerals, Metals and Materials Society 60 (11) (2008).

[5] M. Vulcan, Der pneumatische Tiefungsversuch und seine Anwendung in der superplastischen AluminiumBlechumformung, Dissertation, DGM Informationsgesellschaft Verlag, Oberursel, 2006.

[6] D. Banabic, M. Vulcan, K. Siegert, Bulge testing under constant and variable strain rates of superplastic aluminium alloys, 11th CIRP Conference, Antalya, 2005, pp. 205-209.

[7] M. Liewald, J. Kappes, R. Pop, Superplastic forming of magnesium alloys, 65th Annual World Magnesium Conference, 2008, pp. 115-121.

[8] F.K. Abu-Farha, M. Nazzal, R. Curtis, The effects of specimen geometry on the accuracy of tensile testing of metallic superplastic materials, Key Engineering Materials 433 (2010) 325-331.

[9] F.K. Abu-Farha, M.K. Khraisheh, Mechanical characteristics of superplastic deformation of AZ31 magnesium alloy, Journal of Materials Engineering and Performance 
16 (2) (2007) 192-199.

[10] J.J. Blandin, Superplastic forming of magnesium alloys: production of microstructures, superplastic properties, cavitation behaviour, Materials Science Forum 551-552 (2007) 211-217.

[11] U. Draugelates, A. Schram, C.C. Kedenburg, Superplastische Eigenschaften einer konventionellen AM20-Magnesiumlegierung, Materialwissenschaft und Werkstofftechnik 32 (2001), S. 84-87.

[12] A. Galiyev, R. Kaibyshev, Superplasticity in a magnesium alloy subjected to isothermal rolling, Scripta Materialia 51 (2004) 89-93.

[13] H. Iwasaki, T. Mori, M. Mabuchi, T. Tagata, K. Higashi, Temperature and strain-rate dependence of elongation in Al-4.5 Mg alloy, Materials Science Forum 357-359 (2001) 153-158.

[14] M.K. Khraisheh, F.K. Abu-Farha, K.J. Weinmann, Investigations of post-superplastic forming properties of AZ31 magnesium alloy, Annals of the CIRP 56 (2007) 289-292.

[15] M.K. Khraisheh, F.K. Abu-Farha, M.A. Nazzal, K.J. Weinmann, Combined mechanics-materials based optimization of superplastic forming of AZ31 magnesium alloy, Annals of the CIRP, 2006.

[16] D. Sorgente, L. Tricarico, Analysis of different specimen geometries for tensile tests in superplastic conditions for an aluminium alloy, Materials Science Forum 551-552 (2007) 123-128.

[17] F.K. Abu-Farha, N.A. Rawashdeh, M.K. Khraisheh, Superplastic deformation of magnesium alloy AZ31 under biaxial loading condition, Materials Science Forum 551-552 (2007) 219-224.

[18] Y. Aoura, D. Ollivier, A. Ambari, P. Santo, Determination of material parameters for $7475 \mathrm{Al}$ alloy from bulge forming tests at constant stress, Journal of Materials Processing Technology 145 (2004) 352-359.

[19] K.C. Chan, K.K. Chow, Analysis of hot limit strains of a superplastic 5083 aluminum alloy under biaxial tension, International Journal of Mechanical Sciences 44 (2002) 1467-1478.
[20] S.W. Chung, K. Higashi, W.J. Kim, Superplastic gas pressure forming of fine-grained AZ61 magnesium alloy sheet, Materials Science and Engineering A 372 (2004) 15-20.

[21] S. Franchitti, G. Giuliano, G. Palumbo, D. Sorgente, L. Tricarico, On the optimisation of superplastic free forming test of an AZ31 magnesium alloy sheet, 11th International ESAFORM Conference on Material Forming, 2008.

[22] G. Giuliano, Thickness and strain rate at the sheet dome apex in superplastic bulge forming tests, 12th International ESAFORM Conference on Material Forming, 2009.

[23] M.A. Kulas, P.E. Krajewski, J.R. Bradley, E.M. Taleff, Forming limit diagrams for AA5083 under SPF and QPF conditions, Materials Science Forum 551-552 (2007) 129-134.

[24] D. Sorgente, L.D. Scintilla, G. Palumbo, L. Tricarico, Blow forming of AZ31 magnesium alloy at elevated temperatures, International Journal of Material Forming 3 (1) (2010) 13-19.

[25] A.J. Barnes, Superplastic forming 40 years and still growing, Journal of Materials Engineering and Performance 4 (2007) 440-454.

[26] M. Liewald, J. Kappes, Challenging In-situ Strain Measurement in Pneumatic Bulging of AA5083, 14th International ESAFORM Conference on Material Forming, 2011.

[27] D. Elsenheimer, P. Groche, Determination of material properties for hot hydroforming, Production Engineering Research and Development 3 (2009) 165-174.

[28] K.A. Padmanabhan, R.A. Vasin, F.U. Enikeev, Superplastic Flow: Phenomenology and Mechanics, ISBN 3-540-67842-5, Springer-Verlag Berlin Heidelberg, New York, 2001, pp. 71-74.

[29] T. Adamek, Numerische Methoden für Ingenieure, Universität Stuttgart, Institut für Bioverfahrenstechnik 2009, pp. 23-70.

[30] W. Kleppmann, Taschenbuch Versuchsplanung, Carl Hanser Verlag, München, Wien, 2009.

[31] ESI Group, PAM-STAMP 2G \& PAM-TUBE 2G User's Guide, 2009. 